\title{
Carpal tunnel syndrome (CTS) and exposure to vibration, repetitive wrist movements, and heavy manual work: a case-referent study
}

\author{
GUNILLA WIESLANDER,* D NORBÄCK, * C-J GÖTHE，L JUHLIN \\ From the Department of Occupational Medicine, Southern Hospital, S-100 64 Stockholm, and Clinic of Hand \\ Surgery, Sabbatsberg Hospital, S-113 82 Stockholm, Sweden
}

\begin{abstract}
Possible connections between carpal tunnel syndrome (CTS) and exposure to vibrating handheld tools, repetitive wrist movements, and heavy manual work were examined in a case-referent study. The cases were 38 men operated on for CTS between 1974 and 1980 . For each case, two referents were drawn from among other surgical cases (hospital referents) and two further referents from the population register and telephone directory, respectively (population referents). Thirty four of 38 cases $(89 \%)$ and 143 of 152 referents $(94 \%)$ were interviewed by telephone. An increased prevalence of obesity, rheumatoid disease, diabetes, or thyroid disease was observed among the cases but most did not suffer from any of these disorders. CTS was significantly correlated with exposure to vibration from handheld tools and to repetitive wrist movements but showed a weaker correlation with work producing a heavy load on the wrist. A cause-effect relation between CTS and exposures to handheld vibrating tools and to work causing repetitive movements of the wrist seems probable. Some differences between hospital and population referents indicate that a case-referent study of this type could be biased by inappropriate selection of referents.
\end{abstract}

An analysis of symptoms among patients examined at the Southern Hospital (Södersjukhuset) in Stockholm between 1974 and 1980 because of suspected vibration injury showed that 10 of 126 patients $(7 \%)$ had disturbed function of the median nerve distal to the wrist typical of carpal tunnel syndrome (CTS). ${ }^{\prime}$ This observation initiated a case-referent study to examine possible connections between CTS and exposure to vibrating tools, repetitive wrist movements, and heavy manual work. The influence of other factors which could possibly induce CTS such as obesity, rheumatoid arthritis, and some endocrine disorders were also studied.

\section{Material and methods}

The cases were men aged 20-66 who were operated on for CTS by division of the carpal ligament at the Sabbatsberg Hospital during 1975-80. CTS was diagnosed clinically by a hand surgeon, and the diagnosis was confirmed electroneurographically by measure-

*Present address: Department of Occupational Medicine, Akademiska sjukhuset, S-751 85 Uppsala, Sweden.

Accepted 18 January 1988 ment of the conduction velocities in the median nerve at the wrist level. Patients on whom the transverse carpal ligament was divided because of post-traumatic nerve compression were excluded from the study. The remaining 38 patients constituted the cases in this study.

For each case, two referents were drawn from among other surgical cases (hospital referents) and two further referents from the general population register and the telephone directory, respectively (population referents). All referents were matched for sex (only men were included), age ( \pm 3 years), and the hospital referents also for year of operation $( \pm 3$ years).

The hospital referents were collected from the medical register at the Southern Hospital. During 1975-80, the catchment areas for the surgical department of this hospital and the clinic of hand surgery of Sabbatsberg Hospital were similar. For each case, one referent had been operated on for gall bladder disease and the other for varicous veins in the legs.

The population referents were living in the catchment area of the clinic of hand surgery of the Sabbatsberg Hospital. A new population referent was drawn if the first could not be interviewed because of death, severe mental retardation, or admission to a 
mental hospital. The age of the telephone subscribers was obtained from the population register.

Both cases and referents were interviewed on the telephone by the same physician using a standard questionnaire. Information was collected on type of work and occupational exposure up to the day of operation of the corresponding case. The interviews dealt with the use of vibrating handheld tools, performance of repetitive wrist movements at work, and work involving heavy load on the wrist. The degree of exposure was evaluated both with regard to the total number of work years and the average number of exposed hours a week. The performance of repetitive wrist movements at work was classified independently by the person interviewed and an occupational hygienist. Exposure to repetitive wrist movements was considered to exist if both agreed and the number of exposure years was defined as the average of their evaluations.

Reference weights were calculated from tables published by Bengtsson et al, ${ }^{2}$ and obesity was defined as a body weight exceeding the reference weight by more than $10 \%$. Any information about rheumatoid arthritis, diabetes, and thyroid gland disease was noted.

Four of the 38 cases $(11 \%)$ were not interviewed; one had moved abroad and three had no telephone. The corresponding figures for the hospital referents were seven of $76(9 \%)$; four had no telephone, two had a secret telephone number, and one was not found for unknown reasons. Two of the 76 population referents (3\%) were not interviewed; one had moved abroad and one could not be found for unknown reasons.

Chi-squared statistics were used to calculate two sided $\mathrm{p}$ values for the differences between cases and referents, odds ratios, and $95 \%$ confidence intervals of the odds ratios. The Mantel-Haenszel procedure was used to calculate the total odds ratio and stratification was used to calculate odds ratios for multiple categories. $^{3}$

The study was examined and approved by the ethical committee of the Southern Medical Services District in the County of Stockholm.

\section{Results}

There was a significantly higher proportion of subjects with occupational exposure to handheld vibrating tools and repetitive movements of the wrist among the cases than among the referents (table 1). For both types of exposure, the odds ratios tended to increase with increasing exposure time. The proportion of subjects with work causing a great load on the wrist, however, did not differ significantly between cases and referents, although the odds ratios did tend to increase with increasing period of exposure.
The odds ratios for diabetes mellitus, thyroid, ands rheumatoid diseases were, throughout, numerically? larger than 1 , but the numbers were too small to permit statistical analysis of the separate diseases (table 2) The proportion of subjects with at least one of these diseases, however, was significantly higher among the cases than among the referents. The frequency of obese individuals and current smokers did not differ significantly between cases and referents.

The proportion of persons with obesity and尺 occupational exposure to both handheld vibratings tools, repetitive movements of the wrist, and a great load on the wrist was significantly higher among thehospital than among the population referents (table 3 ) $\vec{\omega}$ There were, however, no significant differences? between the two referent groups for smoking habits ord occurrence of diabetes mellitus, thyroid disease, or rheumatoid arthritis.

As may be seen in table 4, the proportion of office workers was lowest among the cases $(12 \%)$ and $\omega$ highest among the population referents $(46 \%)$. The unequal distribution of the total material is significant $(p<0.005)$ as are the differences between cases and population referents $(p<0.001)$ and hospital and population referents $(p<0.005)$. The difference between cases and hospital referents, however, is non-significant $(p>0 \cdot 10)$.

There were significant differences (table 5) betwegn ${ }^{\infty}$ hospital and population referents with regard to so of the variables analysed in table 3 . A comparison the data in tables 1 and 5 shows that the odds ratios CTS coupled to work with vibrating tools ando repetitive movements or great load on the wrists ared highest when the referent group is restricted to popula-

Table 1 Odds ratios of some occupational exposures among 34 cases with CTS by comparison with 143 referents

\begin{tabular}{|c|c|c|c|c|}
\hline Exposure & Cases & $\begin{array}{l}\text { No of } \\
\text { Referents }\end{array}$ & $\begin{array}{l}\text { Odds ratio } \\
(95 \% \mathrm{CI})\end{array}$ & $\begin{array}{l}\text { Two sidt } \\
p \text { value }\end{array}$ \\
\hline \multicolumn{5}{|c|}{ Use of hand held vibrating tools: } \\
\hline$<1$ year & 21 & 120 & $1 \cdot 0$ & - \\
\hline $1-20$ years & 8 & 17 & $2 \cdot 7(1 \cdot 1-6 \cdot 7)$ & 0.04 \\
\hline $\begin{array}{c}>20 \text { years } \\
\text { Mantel-Haenszel }\end{array}$ & 5 & 6 & $4.8(1.5-15 \cdot 6)$ & 0.01 \\
\hline estimate & 34 & 143 & $3.3(1.6-6.8)$ & 0.002 \\
\hline \multicolumn{5}{|c|}{ Repetitive movements of wrist: } \\
\hline$<1$ year & 20 & 113 & 1.0 & - \\
\hline $\begin{array}{l}1-20 \text { years } \\
>20 \text { years }\end{array}$ & $\begin{array}{l}5 \\
9\end{array}$ & $\begin{array}{l}19 \\
11\end{array}$ & $\begin{array}{l}1.5(0.5-4.4) \\
4.6(1.8-11.9)\end{array}$ & $\begin{array}{l}\text { NS } \\
0.002\end{array}$ \\
\hline $\begin{array}{l}\text { Mantel-Haenszel } \\
\text { estimate }\end{array}$ & 34 & 143 & $2 \cdot 7(1 \cdot 3-5 \cdot 4)$ & 0.006 \\
\hline \multicolumn{5}{|c|}{ Work causing great load on wrist: } \\
\hline $\begin{array}{c}<1 \text { year } \\
1-20 \text { years } \\
>20 \text { years } \\
\text { Mantel-Haenszel }\end{array}$ & $\begin{array}{r}14 \\
12 \\
8\end{array}$ & $\begin{array}{l}80 \\
41 \\
22\end{array}$ & $\begin{array}{l}1 \cdot 0 \\
1.7(0.7-3.9) \\
2 \cdot 1(0.8-5 \cdot 5)\end{array}$ & $\begin{array}{l}- \\
\text { NSS }\end{array}$ \\
\hline estimate & 34 & 143 & $1.8(0.96-3.5)$ & NS \\
\hline
\end{tabular}


Table 2 Odds ratios of some diseases, obesity, and smoking among 34 cases with CTS by comparison with 143 referents

\begin{tabular}{|c|c|c|c|c|c|c|}
\hline \multirow[b]{2}{*}{ Exposure } & \multicolumn{2}{|c|}{ Cases } & \multicolumn{2}{|c|}{ Referents } & \multirow[b]{2}{*}{ Odds ratio $(95 \% \mathrm{CI})$} & \multirow[b]{2}{*}{ Two sided $p$ value } \\
\hline & No & $\%$ & No & $\%$ & & \\
\hline $\begin{array}{l}\text { Diabetes mellitus } \\
\text { Rheumatoid arthritis } \\
\text { Thyroid disease } \\
\text { Any of the diseases mentioned above } \\
\text { Obesity ( }>10 \% \text { above reference weight) } \\
\text { Current smoker }\end{array}$ & $\begin{array}{r}2 \\
4 \\
1 \\
7 \\
9 \\
11\end{array}$ & $\begin{array}{r}6 \\
12 \\
3 \\
21 \\
26 \\
32\end{array}$ & $\begin{array}{r}6 \\
8 \\
1 \\
12 \\
22 \\
34\end{array}$ & $\begin{array}{c}4 \\
6 \\
1 \\
8^{*} \\
15^{*} \\
24\end{array}$ & $\begin{array}{l}1 \cdot 4 \\
2 \cdot 3 \\
4 \cdot 6 \\
2 \cdot 8(1 \cdot 04-7 \cdot 6) \\
2 \cdot 0(0 \cdot 8-4 \cdot 8) \\
1 \cdot 5(0 \cdot 7-3 \cdot 5)\end{array}$ & $\begin{array}{l}- \\
\overline{-} \\
0 \cdot 04 \\
\text { NS } \\
\text { NS }\end{array}$ \\
\hline
\end{tabular}

*Incomplete answer from one referent.

Table 3 Odds ratios of some occupational exposures, some diseases, obesity, and smoking among 69 hospital referents by comparison with 74 population referents

\begin{tabular}{|c|c|c|c|c|c|c|}
\hline \multirow[b]{3}{*}{ Exposure } & \multicolumn{4}{|c|}{ Referents } & \multirow[b]{3}{*}{ Odds ratio $(95 \% \mathrm{CI})$} & \multirow[b]{3}{*}{ Two sided $p$ value } \\
\hline & \multicolumn{2}{|c|}{ Hospital } & \multicolumn{2}{|c|}{ Population } & & \\
\hline & No & $\%$ & $\overline{N o}$ & $\%$ & & \\
\hline $\begin{array}{l}\text { Use of handheld vibrating tools ( }>1 \text { year) } \\
\text { Repetitive movements of wrist ( }>1 \text { year) } \\
\text { Work causing great load on wrist ( }>1 \text { year) } \\
\text { Diabetes mellitus, rheumatoid arthritis, or thyroid }\end{array}$ & $\begin{array}{l}16 \\
20 \\
37\end{array}$ & $\begin{array}{l}23 \\
29 \\
54\end{array}$ & $\begin{array}{r}7 \\
10 \\
26\end{array}$ & $\begin{array}{r}9 \\
14 \\
35\end{array}$ & $\begin{array}{l}2 \cdot 9(1 \cdot 1-7 \cdot 4) \\
2 \cdot 6(1 \cdot 1-6 \cdot 0) \\
2 \cdot 1(1 \cdot 1-4 \cdot 2)\end{array}$ & $\begin{array}{l}0.03 \\
0.02 \\
0.03\end{array}$ \\
\hline $\begin{array}{l}\text { disease } \\
\text { Obesity ( }>10 \% \text { above reference weight) } \\
\text { Current smoker }\end{array}$ & $\begin{array}{r}7 \\
15 \\
20\end{array}$ & $\begin{array}{l}10 \\
22 \\
29\end{array}$ & $\begin{array}{r}5 \\
7 \\
14\end{array}$ & $\begin{array}{c}7 \\
9 * \\
19\end{array}$ & $\begin{array}{l}1 \cdot 5(0 \cdot 5-5 \cdot 1) \\
2.6(1.02-6 \cdot 8) \\
1 \cdot 7(0.8-3 \cdot 8)\end{array}$ & $\begin{array}{l}\text { NS } \\
<0.05 \\
\text { NS }\end{array}$ \\
\hline
\end{tabular}

*Incomplete answer from one referent.

Table 4 Proportion of office workers among cases and referents

\begin{tabular}{lccc}
\hline & \multicolumn{2}{c}{ Office worker } & \\
\cline { 2 - 3 } & Yes & No & Total \\
\hline Cases & 4 & 30 & 34 \\
Hospital referents & 16 & 53 & 69 \\
Population referents & 34 & 40 & 74 \\
\hline
\end{tabular}

tion referents. Irrespective of duration of exposure, obesity was more common among the cases than among the population referents.

The subjects were stratified with regard to the number of risk factors of significance in this study. The number of subjects having more than two risk factors was too small for separate analysis. As seen in table 6, the odds ratios tend to increase with increasing number of risk factors.

\section{Discussion}

CTS is more common among women than men. ${ }^{4}$ Women with CTS show an increased prevalence of gynaecological disorders, ${ }^{5}$ and CTS may start during
Table 5 Odds ratios of some occupational exposures and obesity among 34 cases with CTS by comparison with 74 population referents

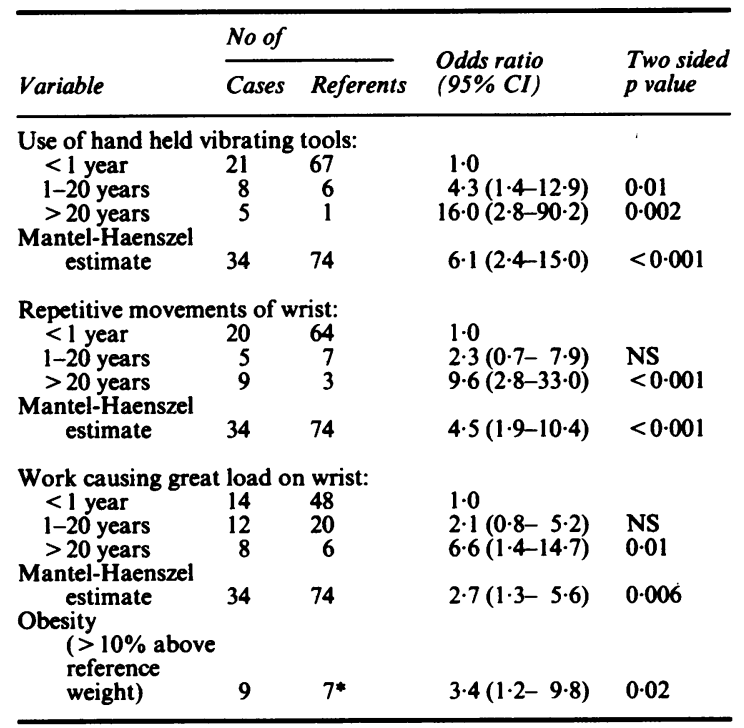

*Incomplete answer from one referent. 
Table 6 Odds ratios correlated with number of risk factors among 34 cases with CTS by comparison with 143 referents

\begin{tabular}{|c|c|c|c|c|}
\hline \multirow[b]{2}{*}{ No of risk factors* } & \multicolumn{2}{|c|}{ No of subjects } & \multirow{2}{*}{$\begin{array}{l}\text { Odds ratio } \\
(95 \% \text { CI })\end{array}$} & \multirow{2}{*}{$\begin{array}{l}\text { Two-sided } \\
\text { p value }\end{array}$} \\
\hline & Cases & Referents & & \\
\hline \multirow[t]{2}{*}{$\begin{array}{l}\text { Zero } \\
\text { One } \\
\text { Two } \\
>2 \\
\text { Mantel-Haenszel } \\
\text { estimate }\end{array}$} & $\begin{array}{r}12 \\
8 \\
8 \\
6\end{array}$ & $\begin{array}{r}85 \\
34 \\
17 \\
6\end{array}$ & $\begin{array}{l}1 \cdot 0 \\
1 \cdot 7(0 \cdot 6-4 \cdot 4) \\
3 \cdot 3(1 \cdot 2-9 \cdot 1) \\
7 \cdot 1(2 \cdot 2-22 \cdot 7)\end{array}$ & $\begin{array}{c}\text { NS } \\
0.02 \\
<0.001\end{array}$ \\
\hline & 34 & 142 & $2.9(1.6-5.2)$ & $<0.001$ \\
\hline
\end{tabular}

*Each individual can have $0-4$ of the following risk factors: vibration exposure $>1$ year; repetitive movements of the wrist $>1$ year; any of the diseases mentioned in table 2; obesity ( $>10 \%$ above reference weight).

pregnancy or in the puerperium. ${ }^{07}$ Rheumatoid arthritis, ${ }^{89}$ obesity, ${ }^{10}$ and endocrine disorders such as diabetes mellitus ${ }^{112}$ and thyroid disease ${ }^{13}$ have been reported to increase the incidence of CTS.

In the present study an increased prevalence of obesity, rheumatoid disease, diabetes, or thyroid disease was found among the cases with CTS. Most, however, did not suffer from any of these disorders, indicating that they are of minor importance in this connection. In vibration exposed groups smoking or taking snuff are linked to an increased risk of developing traumatic vasospastic disease ${ }^{14}$ but the results do not indicate that exposure to nicotine is related to CTS in a similar way.

There is an association between exposure to handheld vibrating tools and the occurrence of CTS, ${ }^{515-18}$ and a connection between CTS and repetitive hand movements has also been observed in, for example, cleaning workers ${ }^{19}$ and butchers. ${ }^{10}$ Work with deviated wrists and pinched hand positions is associated with CTS in women with sewing jobs, ${ }^{4}$ and positive associations between cumulative trauma disorders (CTS being one of the diagnoses included in this condition) and high force-high repetitive manual jobs have been observed. ${ }^{20}$ In a postmortem study histological changes were observed, especially in the most frequently flexed and extended wrist area, suggesting a connection between CTS and repeated exertions with flexed or extended wrists. ${ }^{21}$

The results presented here confirm that exposure to handheld vibrating tools, work causing repetitive movements of the wrist, and possibly also work causing heavy load on the wrist are of importance for the development of CTS. These exposures are often related to each other making it difficult to examine the separate effects in a study such as this. CTS, however, seems to be more closely related to exposure to vibrations from handheld tools and to repetitive wrist movements than to heavy loads on the wrist.

Case-referent studies are sensitive to selection bias causing both false negative and false positive results, ${ }^{22}$ but the significance of occupational factors for CTS was seldom taken into consideration during the 1970s? making it unlikely that the cases, which were operate on between 1975 and 1980 were subject to ang. significant selection bias. Nevertheless, the observef: differences between hospital and population referents indicate that a case-referent study of this type could be biased by the inappropriate selection of referents.

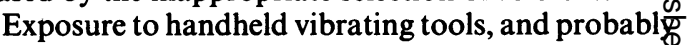
also to repetitive movements in the wrist, is more common in blue collar than in white collar professions Blue collar workers tend to accumulate in inpatient5 groups as compared with white collar workers, ${ }^{23}$ and the differences between cases and referents for suctu exposures tend to be smaller when the referents are्छ collected from inpatients than when they are collecte $\$$ from the total population. Norell and Ahlbom have found that a study of this type could be affected b\$ selection bias because hospital referents tend to con $\overrightarrow{-}$ ceal effects due to the exposure under examination. The observed dose response relations and th\& demonstrated additive effects of different risk factors indicate a cause-effect relation between CTS and exposures to handheld vibrating tools and possible also to work causing repetitive movements of the wrist.

\section{References}

1 Wieslander G, Ekenvall L, Göthe CJ. Vibration induced neuæDlogical damage. In: Proceedings of the international symposium on the protection of workers against vibration, Nis, 1982. Geneva:응 International Labour Office, 1982:67-70.

2 Bengtsson C, Hultén B, Larsson B, Noppa H, Steen B, Warnold J New weight-height tables in Swedish middle aged and elderly men and women. Lakartidningen 1981;98:3152-4. (In Swedish, summary in English.)

3 Axelsson O. Epidemiology in occupational and environmentax health. Lund: Studentlitteratur, 1981. (In Swedish.)

4 Armstrong TJ, Chaffin DB. Carpal tunnel syndrome and selected뮤 personal attributes. J Occup Med 1979;21:481-6.

5 Cannon LJ, Bernacki EJ, Walter SD. Personal and occupationalo factors associated with carpal tunnel syndrome. J Occup Med 1981;23:255-8.

6 Snell NJC, Coysh HL, Snell BJ. Carpal tunnel syndrome present-을 ing in the puerperium. Practitioner 1980;224:191-3.

7 Voitk AJ, Mueller JC, Farlinger JE, Johnston RU. Carpal tunnelo syndrome in pregnancy. Can Med Assoc J 1983;128:277-81.

8 Chamberlain MA, Corbett M. Carpal tunnel syndrome in early rheumatoid arthritis. Ann Rheum Dis 1970;29:149-52.

9 Lang H, Kalliomäki JL, Puusa A, Halonen JP. Sensory neuropathy in rheumatoid arthritis: an electroneurographic study ? Scand J Rheumatol 1981;10:81-4.

10 Falck B, Aarnio P. Left-sided carpal tunnel syndrome in butchers. Scand J Work Environ Health 1983;9:291-7.

11 Mulder DW, Lambert EH, Bastron JA, Sprague RG. The neuropathies associated with diabetes mellitus. A clinical and electromyographic study of 103 unselected diabetic patients. Neurology 1961;11:275-84.

12 Phalen GS. The carpal tunnel syndrome. Seventeen years' ex-? perience in diagnosis and treatment of six hundred and fifty- $\mathrm{T}$ four cases. J Bone Joint Surg 1966;48-A:211-28. 
13 Hybbinette $\mathrm{CH}$, Mannerfelt L. The carpal tunnel syndrome. Lakartidningen 1974;71:3283-5. (In Swedish, summary in English.)

14 Ekenvall L, Lindblad LE. Vibration induced white fingers and nicotine-a preliminary report. Opuscula Medica Sthlm 1985; 30:28-31. (In Swedish, summary in English.)

15 Abbruzzese M, Loeb C, Ratto S, Sacco G. A comparative electrophysiological and histological study of sensory conduction velocity and Meissner corpuscles of the median nerve in pneumatic tool workers. Eur Neurol 1977;16:106-14.

16 Rothfleish S, Sherman D. Carpal tunnel syndrome. Biomechanical aspects of occupational occurrence and implications regarding surgical management. Orthopaedics Review 1978;7:107-9.

17 Ahlborg G, Voog L, de Laval J, Glad JH. Carpal tunnel syndrome (II): a case-control study. Lakartidningen 1982;79:4907-8. (In Swedish.)

18 Chatterjee DS, Barwick DD, Petrie A. Exploratory electromyography in the study of vibration-induced white fingers in rock drillers. Br J Ind Med 1982;39:89-97.

19 Fati S, Fiorellino G, Nasti G, Ferraro L. Incidence of carpal tunnel syndrome in auxillary hospital workers. Rivista di Medicina del Lavoro ed Igiene Industriale 1980;4:95-102. (In Italian, summary in English.)

20 Silverstein BA, Fine LJ, Armstrong TJ. Hand wrist cumulative trauma disorders in industry. Br J Ind Med 1986;43:779-84.

21 Armstrong TJ, Castelli WA, Evans FG, Diaz-Perez R. Some histological changes in carpal tunnel contents and their biomechanical implications. J Occup Med 1984;26:197-201.

22 Lilienfeld AM, Lilienfeld DE. Foundations of epidemiology. 2nd ed. New York: Oxford University Press, 1980.

23 Dahlgren G, Spetz CL. Facts about illness and its social and occupational distribution in Sweden. Stockholm: National Swedish Social Welfare Board, 1983. (In Swedish.)

24 Norell SE, Ahlbom A. Hospital versus population referents in two case-referent studies. Scand J Work Environ Health 1987;13: 62-6.

\section{Vancouver style}

All manuscripts submitted to the $\mathrm{Br} J$ Ind $\mathrm{Med}$ should conform to the uniform requirements for manuscripts submitted to biomedical journals (known as the Vancouver style)

The $B r J$ Ind Med, together with many other international biomedical journals, has agreed to accept articles prepared in accordance with the Vancouver style. The style (described in full in Br Med J, 24 February 1979, p 532) is intended to standardise requirements for authors.

References should be numbered consecutively in the order in which they are first mentioned in the text by Arabic numerals above the line on each occasion the reference is cited (Manson ${ }^{1}$ confirmed other reports ${ }^{2-5} \ldots$ ). In future references to papers submitted to the $\mathrm{Br} J$ Ind Med should include: the names of all authors if there are six or less or, if there are more, the first three followed by et al; the title of journal articles or book chapters; the titles of journals abbreviated according to the style of Index Medicus; and the first and final page numbers of the article or chapter.

Examples of common forms of references are:

1 International Steering Committee of Medical Editors. Uniform requirements for manuscripts submitted to biomedical journals. Br Med J 1979;1:532-5.

2 Soter NA, Wasserman SI, Austen KF. Cold urticaria: release into the circulation of histamine and eosino-phil chemotactic factor of anaphylaxis during cold challenge. $N$ Engl J Med 1976;294:687-90.

3 Weinstein L, Swartz MN. Pathogenic properties of invading micro-organisms. In: Sodeman WA Jr, Sodeman WA, eds. Pathologic physiology: mechanisms of disease. Philadelphia: W B Saunders, 1974:457-72. 